\title{
THE TRANSITION TO BIOECONOMY
}

Please cite this article as:

Dinu, V., 2019. The Transition to Bioeconomy. Amfiteatru Economic, 21(50), pp. 5-7.

DOI: $10.24818 / \mathrm{EA} / 2019 / 50 / 5$

Developed and developing countries face social, economic and environmental challenges. These are the dimensions of sustainability, and the future of mankind depends on the transition from a linear economy towards bioeconomy. This shift represents a challenge for the EU itself due to several factors, such as the economic disparities between the Member States, the lack of concrete national and regional bio-economic strategies, their poor application and correlation, etc. At the same time, within the contemporary period, this transition is one of the most important priorities in the world, capturing the attention of political decision-makers, industry representatives and researchers.

The development of the bioeconomy relies on new knowledge and technologies, however, it faces numerous risks and uncertainties. These challenges can be approached from a human behavior perspective, which includes, among other topics, individual and social decision making process, risk and loss aversion and human reacting at specific economic situations.

For a sustainable bioeconomic development, in addition to biotechnological advancement, social transformation is also required. New market opportunities will appear as long as new created biotechnology products will provide significant benefits for consumers, society and the environment. Further development of bioeconomy will influence and be influenced by the public support and changing attitudes.

These aspects being given, the complexity and novelty of this phenomenon require additional research that would result in innovative concepts, ideas and models. Thus, in this issue of the Amfiteatru Economic journal, papers which investigate issues related to the transition from classical economy to bioeconomy are being set forth.

Based on data from EUROSTAT official statistics, plus data collected under the Eurobarometer 88.1, from the European Commission and the European Parliament, the article "Transition to bioeconomy: perceptions and behaviors in Central and Eastern Europe" contributes to better understanding the concept and policies of bioeconomy, by also making a comparative analysis to identify differences and similarities between national systems regarding the citizens' behaviors and perceptions about the development of bio-economy in Central and Eastern European countries. 
The article "Economic modeling in the management of transition to bioeconomy" presents, in a first part, the conceptual model of the transition process, making a review of the specialized literature. The authors confer practicability to the sustainable economic model developed in the primary sector, as the first biomass-generating industry, founded at the base of production in the secondary and tertiary sectors. The second part of the article defines the behavioral research model. The authors propose to provide an applicative perspective to the behavioral model, through the economic integration of the statistically collected data from the biomass industry. The third part of the article presents the results of the case study, interpreted in the light of the responses to the questionnaire submitted by the respondents.

The paper on "The clarity of the information regarding the bioeconomy: an analysis of the reports published by the organizations" aims to evaluate the clarity of information presented in reports published by organizations, made for both financial and non-financial information (containing bio-economic data). In this manner, a feedback is provided to organizations regarding the way in which they can improve the clarity of their published reports.

The creation of green jobs is a basic component for the implementation of bioeconomic mechanisms alongside other factors, such as gross domestic product growth, environmental protection and national security. Within the article "Green jobs creation - main element in the implementation of bioeconomic mechanisms" it is elaborated a profile of companies willing to create new jobs. The study brings as a novelty element the construction of an efficient resource use index that requires the implementation of a set of ecological measures and proves to be an important tool in the context of creating green jobs.

Taking into account the major differences between the Member States of the European Union regarding the implementation of the sustainable development goals stipulated by the United Nations and the transition from the fossil fuel economy to the one based on the principles of bioeconomics, the paper entitled "The role of bioenergy in transition to a sustainable bioeconomy - study on EU countries" proposes highlighting the existing correlation between bioenergy production and a range of economic, environmental or innovation indicators for each Member State. The article presents the gap between states regarding bioenergy, as well as their evolution during the analyzed period.

"Approaching the bioeconomy in terms of increasing the energy efficiency of households in Romania" deals with aspects specific to the transition to the bioeconomy from the consumer perspective, its attitude in the decision making process regarding the adoption of systems based on renewable energy within households. 
The research regarding „Pro-environmental behavior and bioeconomy: reflections on single-bottled water consumption" assesses the behavioral intentions adopted by Romanian students when it comes to the use of bottled water for single use, by implementing an ecologically active behavioral model.

The paper "The role of personal motivation in sustainable purchasing practices" analyzes the impact of motivational factors on practices used by companies to buy organic products, highlighting the role and the motivational foundation of personal attitudes.

Drawing from an exploratory study on "German students' perception of bioeconomy - an exploratory study" the article highlights the role of education and higher education institutions in social transformation processes, and through quantitative and qualitative analysis and assessment it brings to the forefront the perception of students at two German universities on bioeconomy and sustainability.

The transition to bioeconomy is a long-lasting process that requires the involvement of all actors - economic, political, social, and the most important challenges are ensuring food security, sustainable natural resource management, reducing the dependence on non-renewable resources, mitigating and adapting to climate change, and creating jobs, while at the same time achieving the necessary economic growth, so as to ensure the well-being of the citizens.

Editor in Chief,

Vasile Dinu 